\title{
Silent night: retrospective database study assessing possibility of "weekend effect" in palliative care
}

\author{
(9) $\Theta($ OPEN ACCESS
}

\author{
Raymond Voltz director ${ }^{1}$, Robert Kamps consultant physician ${ }^{2}$, Ralf Greinwald lawyer ${ }^{1}$, Martin \\ Hellmich professor ${ }^{3}$, Stefanie Hamacher research associate ${ }^{3}$, Gerhild Becker professor ${ }^{4}$ director ${ }^{5}$, \\ Kathrin Kuhr research associate ${ }^{3}$, Jan Gaertner senior consultant ${ }^{4}$ senior researcher $^{5}$
}

${ }^{1}$ Department of Palliative Care, University Hospital Cologne, Cologne, Germany; ${ }^{2}$ Department of Palliative Care, Medical Clinic of St Katharinen Hospital, Frechen, Germany; ${ }^{3}$ Institute of Medical Statistics, Informatics and Epidemiology, University of Cologne, Cologne, Germany; ${ }^{4}$ Department of Palliative Care, University Hospital Freiburg, 79106 Freiburg, Germany; ${ }^{5}$ Competence Center Palliative Care, Baden-Württemberg, Germany

\begin{abstract}
Objective To compare the mortality of patients in a palliative care unit on working days with that on weekends and public holidays.

Design Retrospective database study.

Setting Palliative care unit in Germany.

Population All admissions to palliative care unit between 1 January 1997 and 31 December 2008.

Main outcome measure The impact of day type (working days or weekends and public holidays) on mortality was analysed using Poisson regression models.

Results A total of 2565 admitted patients and 1325 deaths were recorded. Of the deaths, 448 (33.8\%) occurred on weekends and public holidays. The mortality rate on weekends and public holidays was $18 \%$ higher than that on working days (mortality rate ratio $1.18,95 \%$ confidence interval 1.05 to $1.32 ; \mathrm{P}=0.005$ ).
\end{abstract}

Conclusion Patients in the palliative care unit were at higher risk of dying on weekends and public holidays. In the absence of a prospective study, the exact reasons for this correlation are unclear.

\section{Introduction}

The influence of weekends and public holidays on the quality of healthcare and the associated mortality of patients is known as the "weekend effect."1 Authors from intensive care and surgical settings, as well as obstetrics, emergency medicine, and neurology, have reported an effect of weekends and public holidays on inpatient mortality. ${ }^{2-5}$ In retrospective analyses, almost all publications have confirmed such an increased mortality of patients on these days even if the results were adjusted for potential confounders. ${ }^{6}$ Most authors have assumed that a decreased availability of trained healthcare professionals and deficits in the continuity of care were responsible for the increase in mortality. ${ }^{7-9}$

Many inpatient palliative care units admit exclusively or predominantly severely ill patients in far advanced stages of a disease, for whom prolongation of life is not a realistic treatment goal. ${ }^{10}$ Therefore, one would not assume such a "weekend effect" in this setting. A thoroughly performed review of the available literature did not find any studies that examined this question from a palliative care perspective. Therefore, we did a retrospective review of admissions in the years 1997 to 2008 to compare the mortality of patients in a palliative care unit on working days with that on weekends and public holidays.

\section{Methods}

We retrospectively analysed the admissions to our palliative care unit from 1 January 1997 to 31 December 2008. We retrieved data from the hospital's electronic admission and discharge system. The database provided daily numbers of discharged or deceased patients and the hospital room occupancy. Double counts (two patients per bed per day) were possible if a patient was discharged (or died) and another patient was admitted to this room (bed) the same day. The database does not provide pooled or individual demographic (for example, sex or age) or clinical data. Therefore, approval by the local ethics committee and informed consent were not necessary.

The palliative care unit analysed was an inpatient ward with 15 regular beds. Patients admitted were almost exclusively in the final stage of cancer with complex symptoms and no or very limited options for disease modifying or life prolonging treatment. Admissions to the palliative care unit were more frequent on working days, so the room occupancy differed 
between working days and weekends/public holidays. On weekends and public holidays, staffing levels were reduced (absence of grand rounds; one single physician's round on Saturday; one nurse less during daytime; physiotherapy limited to patients with special needs; no psycho-oncology, music, or art therapy available; spiritual care only on special demand). The training level of staff (experience) was not reduced on weekends and public holidays.

We analysed the effect of day type on mortality by using a Poisson regression model including the exposure (that is, the number of patients on the palliative care unit on each day) as an offset term. To account for differences in room occupancy structure, we fitted a second Poisson regression model including room occupancy (three categories: $<10$ patients, $10-15$ patients, $>15$ patients) as a confounder. We reported mortality rate ratios with corresponding $95 \%$ confidence intervals and $\mathrm{P}$ values (Wald test) for both regression models. ${ }^{11}$ All $\mathrm{P}$ values were generated using two sided tests. The analyses were regarded as explorative, and we present the $\mathrm{P}$ values for descriptive reasons only. We used R version 3.0.2 for statistical analysis.

\section{Results}

The study period covered 4383 days (3001 working days, 1382 weekends and public holidays). During this time, 2565 patients were admitted; the average number of patients in the palliative care unit was 11.7 (range 3-21). A total of 1325 deaths were recorded, with a maximal number of three deaths a day (table $1 \Downarrow)$. We found a considerable effect of day type on mortality: the mortality rate on weekends and public holidays was $18 \%$ higher than that on working days (mortality rate ratio 1.18, 95\% confidence interval 1.05 to $1.32 ; \mathrm{P}=0.005$ ). The room occupancy differed between weekends/public holidays and working days (table $2 \Downarrow$ ). After adjustment for occupancy structure, the effect of day type on mortality was reduced but still noticeable (mortality rate ratio $1.14,1.02$ to $1.28 ; \mathrm{P}=0.025$ ). To capture over-dispersion, we fitted quasi-Poisson models in a sensitivity analysis; this adjustment made little difference (data not shown).

\section{Discussion}

On weekends and public holidays, specialist staff are not as available as on normal working days in many clinical settings. This can affect the quality and type of medical care, with the associated higher mortality in patients that is known as the weekend effect. ${ }^{12}$ Palliative care focuses on the prevention and reduction of suffering rather than the prolongation of life..$^{13}$

Therefore, one would not assume such a weekend effect in this setting. Surprisingly, our study provides strong indications for an increased mortality in palliative care on weekends and public holidays.

\section{Strengths and weaknesses of study}

A thoroughly performed review of the available literature did not find any previous studies that examined this research question for palliative care and only one for haemato-oncology. ${ }^{14}$ As with any retrospective and single centre study, the results of this investigation may have been influenced by confounding factors. As this was a database study, we were unable to adjust for potentially confounding factors such as age, sex, performance status, type of cancer, or patient reported outcomes. On the other hand, the findings of this study might have been even more compelling if an even more vulnerable subgroup of patients (for example, reduced performance state, severe symptoms) had been evaluated.

\section{Comparison with other studies}

Most studies report that on normal acute inpatient wards, significantly more patients die on weekends and public holidays than on regular working days. For example, one study reported significantly higher death rates at weekends than on working days for all patients treated in 72 German medical centres. ${ }^{15}$ In particular, the weekend effect for emergency admissions accounts for a $20 \%$ increased risk of death in the hospital. ${ }^{16}$ Other investigations of critically ill patients confirmed this result. Kostis et al reported a significantly higher 30 day mortality of patients with myocardial infarction in those who were admitted at weekends. ${ }^{17}$ Saposnik et al reported similar findings for patients with a cerebral insult. ${ }^{18}$ The only study in an oncology setting is the study of Bejanyan et al, ${ }^{14}$ who examined a subgroup of patients with acute myeloid leukaemia and reported a significant delay in the placement of triple lumen catheters. The authors used this as a surrogate measure for the quality of care for these patients.

None of the previous studies was able to provide exact explanations for the phenomenon of increased mortality on weekends and public holidays, but different reasons are discussed. For example, Bell at al argue that on weekends and public holidays the number of the medical and non-medical employees present in hospitals is clearly lower than on normal working days. ${ }^{3}$ Alspach et al assume that a reduction in the continuity of medical care and delayed reporting of diagnostic or therapeutic test results occur during weekends and public holidays. ${ }^{19}$ Other authors point out that doctors who are on call on weekends and public holidays are rather inexperienced compared with those working on regular working days, which may result in a reduced quality of invasive procedures and a temporal delay of therapeutic decisions. ${ }^{17} 20$

\section{Meaning of study}

Although most of the studies discussed above evaluated admissions on weekends and public holidays in acute care settings, the potential reasons for a weekend effect theoretically also apply to inpatient palliative care. However, we did not expect equal findings. Of course, many symptoms such as pain or dyspnoea require speedily interventions (for example, opioid or benzodiazepine titration), and paracentesis or thoracentesis can also be indicated for some palliative care emergencies. On our palliative care unit, however, patients are usually admitted on weekdays. After admission, punctures are usually performed in an anticipatory manner on working days. Therefore, invasive procedures are rarely necessary as a medical emergency on weekends and public holidays in our patient population.

On the other hand, other explanations for our finding remain speculative. For example, some nursing team members think that the reduction or even absence of some routine elements of care (for example, grand rounds, routine laboratory and radiological testing) during weekends and public holidays had a great influence on this result. They argue that the atmosphere on the ward is typically more quiet and "laid back" on weekends and public holidays. They suppose that such a decrease in auditory, physical, or emotional distractions may in fact "allow" severely ill patients to die. Another assumption is that with a possibly greater presence of family visitors on weekends, patients may be more prepared to die with loved ones around them. Also, the proportion of very sick patients may be greater at weekends because others have been discharged home. Although it has been argued that psychological factors can influence the time of death, ${ }^{21}$ the reasons for the weekend effect in the palliative care setting remain unclear. We believe that the 
slightly reduced number of staff on weekends and public holidays is not responsible for the higher mortality. We also believe that "working attitude" is not different on weekends and public holidays. However, this is unproved. To identify risk factors and the exact reasons for our findings, a prospective study assessing demographic and clinical data together with a parallel examination of healthcare providers' perceptions would have been necessary.

\section{Conclusion}

Palliative care inpatients were at a higher risk of dying on weekends and public holidays than on normal working days. In the absence of a prospective study, the exact reasons for this correlation are unclear.

Contributors: RV made substantial contributions to interpretation of data and critical revision of the work for important intellectual content. RK and $R G$ made substantial contributions to the conception and drafting of the work. MH and KK made substantial contributions to the conception and design, interpretation of data, and critical revision of the work for important intellectual content. SH made substantial contributions to the interpretation of data and critical revision of the work for important intellectual content. GB contributed to critical revision of the work for important intellectual content. JG made substantial contributions to the conception and design of the work; the acquisition, analysis, and interpretation of data for the work; and drafting the work and revising it critically for important intellectual content. All authors approved the final version to be published. JG is the guarantor.

Funding: None.

Competing interests: All authors have completed the ICMJE uniform disclosure form at www.icmje.org/coi_disclosure.pdf (available on request from the corresponding author) and declare: no support from any organisation for the submitted work; no financial relationships with any organisations that might have an interest in the submitted work in the previous three years; no other relationships or activities that could appear to have influenced the submitted work.

Ethical approval: Not needed.

Transparency: The lead author (the manuscript's guarantor) affirms that the manuscript is an honest, accurate, and transparent account of the study being reported; that no important aspects of the study have been omitted; and that any discrepancies from the study as planned (and, if relevant, registered) have been explained.

Data sharing: The statistical codes and full dataset are available from the corresponding author.
1 Cram P, Hillis SL, Barnett M, Rosenthal GE. Effects of weekend admission and hospital teaching status on in-hospital mortality. Am J Med 2004;117:151-7.

2 Fang J, Saposnik G, Silver FL, Kapral MK. Association between weekend hospital presentation and stroke fatality. Neurology 2010;75:1589-96.

3 Bell CM, Redelmeier DA. Mortality among patients admitted to hospitals on weekends as compared with weekdays. N Engl J Med 2001;345:663-8.

4 Halm EA, Chassin MR. Why do hospital death rates vary? N Engl J Med 2001;345:692-4.

5 Ibrahimou B, Salihu HM, English G, Anozie C, Lartey G, Dagne G. Twins born over weekends: are they at risk for elevated infant mortality? Arch Gynecol Obstet 2012;286:1349-55

6 Mohammed MA, Sidhu KS, Rudge G, Stevens AJ. Weekend admission to hospital has a higher risk of death in the elective setting than in the emergency setting: a retrospective database study of national health service hospitals in England. BMC Health Serv Res 2012;12:87

7 Anderson Cl, Nelson CS, Graham CF, Mosher BD, Gohil KN, Morrison CA, et al. Disorganized care: the findings of an iterative, in-depth analysis of surgical morbidity and mortality. J Surg Res 2012;177:43-8.

8 Schneider EB, Hirani SA, Hambridge HL, Haut ER, Carlini AR, Castillo RC, et al. Beating the weekend trend: increased mortality in older adult traumatic brain injury (TBI) patients admitted on weekends. J Surg Res 2012;177:295-300.

9 Gallerani M, Imberti D, Bossone E, Eagle KA, Manfredini R. Higher mortality in patients hospitalized for acute aortic rupture or dissection during weekends. $J$ Vasc Surg 2012;55:1247-54.

10 Gaertner J, Frechen S, Sladek M, Ostgathe C, Voltz R. Palliative care consultation service and palliative care unit: why do we need both? Oncologist 2012;17:428-35.

11 Kirkwood BR, Sterne JA. Essential medical statistics, 2nd ed. Wiley-Blackwell, 2003:249-62.

12 Sheng A, Ellrodt AG, Agocs L, Tankel N, Weingarten S. Is cardiac test availability a significant factor in weekend delays in discharge for chest pain patients? J Gen Intern Med 1993;8:573-5

13 World Health Organization. Palliative care. WHO, 2007:62

14 Bejanyan N, Fu AZ, Lazaryan A, Fu R, Kalaycio M, Advani A, et al. Impact of weekend admissions on quality of care and outcomes in patients with acute myeloid leukemia. Cancer 2010;116:3614-20.

15 Schwierz C, Augurzky B, Wasem J. Does the quality of hospital treatment vary by days of the week? Ruhr-Universität Bochum (RUB), Department of Economics, 2009.

16 Palmer WL, Bottle A, Davie C, Vincent CA, Aylin P. Dying for the weekend: a retrospective cohort study on the association between day of hospital presentation and the quality and safety of stroke care. Arch Neurol 2012:69:1296-302

17 Kostis WJ, Demissie K, Marcella SW, Shao Y-H, Wilson AC, Moreyra AE. Weekend versus weekday admission and mortality from myocardial infarction. $N$ Engl $J$ Med 2007;356:1099-109.

18 Saposnik G, Baibergenova A, Bayer N, Hachinski V. Weekends: a dangerous time for having a stroke? Stroke J Cereb Circ 2007;38:1211-5.

19 Alspach JG. Weekend admissions to critical care: why do more of these patients die? Crit Care Nurse 2010;30:10-2.

20 Freemantle N, Richardson M, Wood J, Ray D, Khosla S, Shahian D, et al. Weekend hospitalization and additional risk of death: an analysis of inpatient data. $J R$ Soc Med 2012;105:74-84.

21 Phillips DP, Smith DG. Postponement of death until symbolically meaningful occasions. JAMA 1990:263:1947-51.

Accepted: 11 November 2014

\section{Cite this as: BMJ 2014;349:97370}

This is an Open Access article distributed in accordance with the Creative Commons Attribution Non Commercial (CC BY-NC 4.0) license, which permits others to distribute, remix, adapt, build upon this work non-commercially, and license their derivative works on different terms, provided the original work is properly cited and the use is non-commercial. See: http://creativecommons.org/licenses/by-nc/4.0/. 


\section{What is already known on this topic}

The increase in inpatient hospital mortality on weekends and public holidays is known as the weekend effect

Most authors assume that the reduced availability of emergency procedures and senior staff contributes to these findings

\section{What this study adds}

This is the first paper examining a possible weekend effect in a palliative care setting

Patients in the inpatient palliative care ward were at higher risk of dying on weekends and public holidays

The exact reason for this correlation remains unclear

\section{Tables}

Table 1| Number of days, deaths, and patients in palliative care unit by day type

\begin{tabular}{lcccc} 
Day type & No of days & No of deaths & Person days* & Mortality rate (95\% Cl) per 1000 person days \\
Working days & 3001 & 877 & 35692 & $24.6(23.0$ to 26.3$)$ \\
\hline Weekends and public holidays & 1382 & 448 & 15460 & $29.0(26.4$ to 31.8$)$ \\
\hline Total & 4383 & 1325 & 51152 & $25.9(24.5$ to 27.3$)$
\end{tabular}

${ }^{*}$ Cumulative number of patients in palliative care unit. 
Table 2| Room occupancy by day type

\begin{tabular}{cccccc} 
& \multicolumn{5}{c}{ Patients in palliative care unit } \\
\cline { 2 - 5 } Day type & $<10$ & $10-15$ & $>15$ & Total & P value*
\end{tabular}

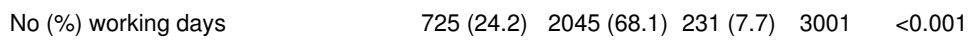

No (\%) weekends and public holidays 441 (31.9) $877(63.5) \quad 64(4.6) \quad 1382$

Total No (\%) $1166(26.6) 2922(66.7) 295(6.7) \quad 4383$

${ }^{*} \chi^{2}$ test. 